\title{
Serebral palsili hastalarda selektif dorsal rizotomi
}

\author{
Selective dorsal rhizotomy in patients with cerebral palsy
}

\author{
Esat Kıter, Adem Çatak
}

Özel Odak Hastanesi, Denizli

Selektif dorsal rizotomi, serebral palsili hastalarda lumbosakral bölgedeki dorsal sinir köklerinin kesilmesini amaçlayan cerrahi bir işlemdir. Hastanın günlük yaşantısına ne kadar katkı verdiği konusu hala tartışmalıdır. Uygun hasta seçiminden sonra hasta işlevine olumlu etkilerinin olduğu ve ortopedik düzeltici cerrahi işlem oranını azalttığı düşünülmektedir.

Anahtar sözcükler: serebral palsi; dorsal rizotomi, selektif; spastisite
Selective dorsal rhizotomy is a surgical procedure aimed to sectioning the dorsal nerve roots of the lumbosacral region in patients with cerebral palsy. It is still controversial how much it contributes to the daily life of the patients. It is believed that it has positive effects on patient function and decreases the rate of orthopedic corrective surgery after selecting the appropriate patient.

Key words: cerebral palsy; dorsal rhizotomy, selective; spasticity
$\mathbf{S}$ pastik serebral palsili hastalar, hayatlarının bir döneminde ortopedi ile ilgili cerrahi bir işleme çok büyük oranda ihtiyaç duyarlar. Zira bu hastaların kas tonusu ve buna bağlı kısa kas boyu, ekstremiteyi sürekli deformasyona zorlayan bir faktördür. Zaman içinde eklemlerdeki kontraktürler ve kemiksel torsiyonlar hastanın duruşunu, oturma pozisyonunu ve hareketliliğini ciddi olarak bozar. Bu nedenle gevşetme ve hatta kemik ile ilgili ameliyatlar kaçınılmaz olur. Rizotomi özellikle spastik diplejik serebral palsi hastalarında lumbosakral dorsal sinir liflerinin kesilmesini amaçlayan cerrahi bir işlemdir. Bu işlem temel olarak serebral palsili (SP) hastalarda deformasyonları cerrahi düzeltmeye gerek kalmadan önlemeyi amaçlar. Illk tanımlayan Foerster, 1908 yılında "tabes dorsalis" hastalarında spastik olmayan plejiyi gözleyince, dorsal sinir köklerinin işlev kaybının spastik hastaların kliniğini düzeltebileceğini düşünmüştür. ${ }^{[1]}$ Dorsal sinir köklerinin kesilmesi ile ilgili cerrahi yöntem yıllar içinde değişime uğramıştır. Dorsal köklerin tamamen kesilmesinin belirgin kas güçsüzlügüne, duyu, propriyosepsiyon ve sfinkter kontrol kaybına yol açması nedeniyle parsiyel olarak kesilebileceği, 1978 yılında
Fasano ve ark. tarafından yapılan çalışma ile gündeme gelmiştir. ${ }^{[2]}$ Elektrofizyolojik mönitörizasyon yardımıyla yapılan "Selektif Dorsal Rizotomi”nin (SDR) ilk kullanımı bu makalede tanımlanmıştır. Daha sonra teknik Peacock ve Arens tarafından güncellenmiş ve işlem alanı L5-S1 laminektomilerinden, konus seviyesinde tek seviye laminektomiye taşınmıştır. ${ }^{[3]}$

\section{GÜNCEL CERRAHI YAKLAŞIM}

Günümüzde önerilen cerrahi teknikte, konus seviyesinden yapılan tek seviye laminektomi veya laminoplasti sonrası, L1-S1 seviyeleri arasında dorsal sinir dallarının kesilmesi amaçlanır. Konus seviyesini insizyon öncesi ultrasonografi ile tespit etmek cerrahi işlemi kolaylaştırır. Konusa ulaşıldıktan sonra hangi sinir kökünün kesileceği ameliyat sırasında nöromonitörizasyonla belirlenir. L1-S1 arasındaki dorsal kökler küçük gruplara bölünerek refleks motor yanıtları nörofizyolojik olarak test edilir. Yanıtlar kaydedilerek evrelendirilir ve bir eşik değeri oluşturulur. En yüksek yanıta sahip kökler kesilir. Bu teknikte konus yaralanması olasılı̆̆ının mevcut olduğu bilinmelidir.

\footnotetext{
- Illetişim adresi: Prof. Dr. Esat Kıter, Özel Odak Hastanesi, Denizli

Tel: 0532 - 3745172 e-posta: esatkiter@gmail.com

- Geliștarihi: 6 Mart $2021 \quad$ Kabul tarihi: 17 Mart 2021
}

ORCID iD: Esat Kıter, 0000-0002-5061-6669 • Adem Çatak, 0000-0002-4443-667x 


\section{SELEKTIF DORSAL RIZOTOMININ SONUÇLARI VE UYGUN HASTA SEÇIMI}

Literatüre baktığımızda, selektif dorsal rizotominin hasta işlevini ne kadar düzelttiğine ve yaşam kalitesini ne kadar artırdığına dair verilerin kanıt düzeyinin düşük olduğunu görürüz. ${ }^{[4,5]}$ Çünkü yayınlarda gerek hasta grubu olsun, gerek yapılan cerrahi müdahale olsun standardizasyonu sağlamak güçtür. Bununla birlikte birçok çalışmada uygun kontrol grubunun olmaması $\mathrm{da}$, elde edilen verilerin güvenilirliğini azaltmaktadır.

Başarılı bir sonuç için her SP hastasının bu cerrahi işlem için uygun aday olmadığının bilinmesi ve hasta seçiminin çok dikkatli yapılması gerekmektedir. Güncel yayınların katkısıyla bu konudaki kriterler daha da netleşmiştir. Hasta yaşının önemli bir faktör olduğu gösterilmiştir. On yaş ve üzeri hastalarda SDR işlemi yerine ortopedik düzeltici cerrahi işlemlerin uzun dönemde daha iyi sonuç verdiği gösterilmiştir. ${ }^{[6]}$ SDR işlemi için en uygun yaşın 10 yaş altı olduğuna inanılır. Özellikle 4-7 yaş arasında yapılan işlemlerin uzun dönemde en iyi sonuçlar verdiği ve ortopedik düzeltici cerrahi ihtiyacını belirgin olarak azalttığı rapor edilmiştir. ${ }^{[7,8]}$ Hasta seçimi ile bir diğer önemli faktör de SP'nin yarattığı işlevsel kısıtlamanın derecesidir. Bu konuda motor işlev ve hareketliliğin değerlendirilmesi gerekir. Genel olarak kabul gören skala sistemi "Kaba Motor İşlev Sınıflaması"dır (Gross Motor Function Classification System -GMFCS) (Tablo 1). . ${ }^{\text {[] }}$ Ağır motor işlev kısıtlaması olan hastalar SDR'den çok fazla yarar görmezler. Cerrahi işlem için en uygun hasta grubu GMFCS II ve III grubu hastalardır. ${ }^{[10-12]}$ Serebral palsinin tipi de SDR işleminin başarısında önemli bir faktördür. Örneğin spastik kuadriplejinin varlığında bu işlemin başarı oranı spastik diplejiye göre belirgin olarak düşüktür. ${ }^{[13]} \mathrm{Bu}$ nedenle SDR işleminin planlanmasında SP tutulumu iyi değerlendirilmelidir. Aquilina ve ark., SDR cerrahisinde hasta seçimiyle ilgili bazı kriterler tanımlamışlardır. Bu kriterlerde, yakın zamanda botulinum toksin uygulaması ya da yakın zamanda geçirilmiş ortopedik cerrahi, nöromonitör sinyallerini etkileyebileceği için SDR cerrahisi açısından olumsuz faktörler olarak kabul edilir (Tablo 2). ${ }^{[11]}$

Yapılan çalışmalara göz attığımızda cerrahi teknik açısından da SDR'nin standardizasyonunun zor olduğunu görüyoruz. L1-S1 arası geniş laminektomi ya da laminoplastinin ameliyat alanını büyüttüğü, bel ağrısı ve postlaminektomi kifozu gibi spinal sorunlara yol açtığı belirtilmiştir. ${ }^{[14]}$ Ayrıca skolyoz ve spondilolistezisin

Tablo 1. Kaba motor işlev ölçütü[ ${ }^{[9]}$

\begin{tabular}{cc}
\hline Kaba Motor İşlev Ölçütü (Gross Motor Function Measure -GMFM) \\
\hline Evre I & Kısıtlama olmaksızın yürür. Ancak koşarken ve zıplarken problem yaşanır. \\
Evre II & Minimum destek veya koltuk değneği ile yürür. Günlük hayatta az miktarda hareket kısıtlılığı yaşanır. \\
Evre III & Yürümek için koltuk değneği veya yürütece ihtiyaç duyar. Günlük hayatta belirgin hareket kısıtılığı vardır. \\
Evre IV & Yürümek veya yürüteci kullanmak için yardıma ihtiyaç duyar. Hareket için tekerlekli sandalye gereklidir. \\
Evre V & Hareket ileri derecede kısıtlıdır. Yerçekimine karşı baş ve gövde kontrolünü sağlayamazlar.
\end{tabular}

Tablo 2. Selektif dorsal rizotomi için cerrahiye uygunluk kriterleri[11]

\begin{tabular}{|c|c|}
\hline Kriter & Açıklama \\
\hline Serebral palsinin tipi & Klasik spastik diplejik SP (ataksi ve distoninin eşlik etmediği) \\
\hline Serebral palsinin ciddiyeti & Kaba Motor İşlev Sınıflaması Evre II ve III \\
\hline Manyetik rezonans (MR) görüntüleme & Bazal ganglionlarda, serebellum ya da beyin sapında yaralanmanın olmaması \\
\hline Kas iskelet sistemi & $\begin{array}{l}\text { Iyi gövde kontrolü, fizik bakıda yerçekimine karşı yeterli direnç, belirgin skolyozun olmaması, } \\
\text { belirgin femur başı subluksasyonunun olmaması }\end{array}$ \\
\hline Önceki işlemler & $\begin{array}{l}\text { Tercihen en son ortopedik cerrahi işlem üzerinden en az bir yıl geçmesi } \\
\text { Tercihen en son botulinum toksini üzerinden en az altı ay geçmesi }\end{array}$ \\
\hline Çocuk ve ailesel faktörler & Fizik tedaviye uyum sağlayacak kooperasyon ve bilişsel yeterlilik \\
\hline
\end{tabular}


bazı serilerde sık gözlendiği rapor edilmiştir. ${ }^{[5]} \mathrm{Bu}$ deformitelerin temel nedeni posterior kemik halkanın çok seviyeli olarak kesilmesidir ve konus seviyesinde yapılan limitli laminektomi ile bu tarz komplikasyonların azaldığı belirtilmiştir. ${ }^{[15]}$ Güncel cerrahi yaklaşım yukarıda anlatılmıştır. Cerrahi sonrası sık gözlenen komplikasyonlardan birisi de kasların güçsüzlüğüdür. Uzun dönemde spastisitenin ve distoninin artması da sık rapor edilen komplikasyonlardandır. Bu yüzden işlem sonrası yoğun bir fizyoterapi programı artık cerrahi işlemin bir parçası olarak kabul edilir. Üriner retansiyon, hipoestezi ve propriyosepsiyon kaybı da beklenen komplikasyonlardandır. İyi yapılmış bir SDR'den sonra genellikle geçici oldukları bildirilmiştir.

Sonuç olarak, SDR işleminden sonra hastanın alt ekstremitesinde spastisitenin azaldığı ve işlevsel olarak olumlu etkilerinin gözlendiğine dair birçok yayın vardır. Ancak GMFCS evresinde pek değişme olmadığı ve bu nedenle işlemin başarısının etkin bir şekilde kaydedilemediği düşünülür. ${ }^{[8,11]}$ Genel olarak SDR işleminin uzun dönemli işlevsel başarısındaki en önemli faktörün uygun hasta seçimi olduğunu söyleyebiliriz.

\section{KAYNAKLAR}

1. Foerster O. Die Behandlung spastischer Lähmungen durch Resektion hinterer Rückenmarkswurzeln. In: Payr E, Küttner $\mathrm{H}$, editors. Ergebnisse der Chirurgie und Orthopädie. Berlin, Heidelberg: Springer; 1911. Crossref

2. Fasano VA, Barolat-Romana G, Ivaldi A, Sguazzi A. Functional posterior radiculotomy, in the treatment of cerebral spasticity. peroperative electric stimulation of posterior roots and its use in the choice of the roots to be sectioned. Neurochirurgie 1976;22:23-34. https://pubmed.ncbi.nlm.nih.gov/958564/

3. Peacock WJ, Arens LJ. Selective posterior rhizotomy for the relief of spasticity in cerebral palsy. S Afr Med J 1982;62:11924. https://pubmed.ncbi.nlm.nih.gov/7089801/

4. Dudley RW, Parolin M, Gagnon B, Saluja R, Yap R, Montpetit K, Ruck J, Poulin C, Cantin MA, Benaroch TE, Farmer JP. Long-term functional benefits of selective dorsal rhizotomy for spastic cerebral palsy. J Neurosurg Pediatr 2013;12:14250. Crossref
5. Tedroff K, Hägglund G, Miller F. Long-term effects of selective dorsal rhizotomy in children with cerebral palsy: a systematic review. Dev Med Child Neurol 2020;62:554-62. Crossref

6. MacWilliams BA, Johnson BA, Shuckra AL, D'Astous JL. Functional decline in children undergoing selective dorsal rhizotomy after age 10. Dev Med Child Neurol 2011;53:71723. Crossref

7. Wright FV, Sheil EM, Drake JM, Wedge JH, Naumann S. Evaluation of selective dorsal rhizotomy for the reduction of spasticity in cerebral palsy: a randomized controlled tria. Dev Med Child Neurol 1998;40:239-47. Crossref

8. FunkJF, Panthen A, Bakir MS, Gruschke F, Sarpong A, Wagner C, Lebek S, Haberl EJ. Predictors for the benefit of selective dorsal rhizotomy. Res Dev Disabil 2015;37:127-34. Crossref

9. Hanna SE, Rosenbaum PL, Bartlett DJ, Palisano RJ, Walter SD, Avery L, Russell DJ. Stability and decline in gross motor function among children and youth with cerebral palsy aged 2 to 21 years. Dev Med Child Neurol 2009;51:295-302. Crossref

10. Josenby $A L$, Wagner $P$, Jarnlo GB, Westbom L, Nordmark E. Functional performance in self-care and mobility after selective dorsal rhizotomy: a 10-year practice-based followup study. Dev Med Child Neurol 2015;57:286-93. Crossref

11. Aquilina K, Graham D, Wimalasundera N. Selective dorsal rhizotomy: an old treatment re-emerging. Arch Dis Child 2015;100:798-802. Crossref

12. Summers J, Coker B, Eddy S, Elstad M, Bunce C, Bourmpaki E, Pennington M, Aquilina K, Cawker S, Edwards R, Goodden J, Hawes S, McCune K, Pettorini B, Smith J, Sneade C, Vloeberghs M, Patrick H, Powell H, Verity C, Peacock JL. Selective Dorsal Rhizotomy Steering Committee. Selective dorsal rhizotomy in ambulant children with cerebral palsy: an observational cohort study. Lancet Child Adolesc Health 2019;3:455-62. Crossref

13. Kim HS, Steinbok P, Wickenheiser D. Predictors of poor outcome after selective dorsal rhizotomy in treatment of spastic cerebral palsy. Childs Nerv Syst 2006;22:60-6. Crossref

14. Grunt S, Becher JG, Vermeulen RJ. Long-term outcome and adverse effects of selective dorsal rhizotomy in children with cerebral palsy: a systematic review. Dev Med Child Neurol 2011;53:490-8. Crossref

15. Park TS, Johnston JM. Surgical techniques of selective dorsal rhizotomy for spastic cerebral palsy. Technical note. Neurosurg Focus 2006 15;21:E7. Crossref 